\title{
A REVIEW OF THE SIGNIFICANT APPROACHES AND THEORIES OF TRANSLATIONS
}

\section{Ms. Urvashi Dave}

\begin{abstract}
This paper aims at a general review of the history of translation theories and approaches from past to present. In this research key theoretical developments are taken into consideration, focusing on the approaches of twentieth century. Different theories of translation emerged at diverse periods. As time passes translation studies emerged as sound independent discipline with the development of translation trends like trends as cultural studies, linguistics, literary theory and criticism, brings a renewed aspect to translation theory, post colonialism etc.
\end{abstract}

Key words: history, approaches, trends, theories, translation, culture.

Different concepts of translation prevailed at different times. Likewise function and status of the translator has also altered. The twentieth century witnesses an immense development in linguistic and other language sciences. The later half of twentieth century focused on translation activity more seriously may be because of the globalization. It is interesting to discover various theories of translation developed throughout the history of translation study. The western translation theory from Cicero to the 20th century revolved around the recurring debate as to whether the translation should be literal or free. In other words, it should be 'word for word' or 'sense for sense'. Translation of the Bible was central to the theories of translation in the west for more than thousand years. Early theorist presented justification for their approach to translation in prefaces to their translations. In the 17th century Dryden discussed three types of translation that is, metaphrase, paraphrase, and imitation. This led to more systematic and accurate definition of translation. Then Schleiermacher's respect for the foreign text had great influence over the scholars. 
Theoreticians of 1950 started looking for more systematic analysis. The focus shifted from the literal and free translation to meaning and equivalence as discussed by Roman Jakobson. After that many scholars attempted to define the nature of equivalence. The most significant among them are, Eugene Nida's concept of formal and dynamic equivalent and the principle of equivalent effect, peter Newmark's semantic and communicative translation and Warner koller's correspondent and aquivalenz.

Eugene Nida's translation theory is called the science of translating. It is developed from his own practical works. His practice took the form of major works in 1960: 'towards science of translating' and 'theory and practice of translation'. In these books Nida tries to look at Bible translation from more scientific point of view with the help of linguistic works of that time. He borrows from semantic and pragmatics and from Chomsky's work on synthetic structure. While analysing individual words, Nida describes different scientific approaches to meaning. He moves away from the old idea that the word had fixed meaning. Meaning is broken down into three categories: linguistic meaning, referential meaning, and emotive or connotative meaning by him. Another technique used by him is semantic structure analysis. What he proposes through this technique is that the sense of a complex semantic term varies and most probably conditioned by its context. This technique is used to clarify ambiguities and to identify cultural differences. It is very useful for those working with very different two languages. The two terms that has been discussed by Nida very deeply are 'Formal equivalence' and 'Dynamic equivalence'. The formal equivalence focuses on message itself while dynamic/ functional equivalent is based on principle of equivalent effect. For Nida, successful translation depends on equivalent effect. According to him the four basic requirements of translation are: 1 . Making sense, 2. Conveying the spirit and manner of the original 3. Having a natural and easy form of expression, and 4 . Producing a similar response. (Nida) Dynamic equivalence works on achieving all these four basic requirements. As a general rule Nida suggested 'correspondence in meaning must have priority over correspondence in style'. The important contribution of Nida in this field is that he took concept of equivalence away from word-for-word equivalence. His formal and dynamic equivalent theory significant role introducing reader cantered orientation to translation theory. Though his systematic analytical 
approach to translation has given birth to heated debate, it has also influenced many prominent scholars like Peter Newmark in the U.K and Werner Koller in Germany.

Newmark's 'Approaches to translation' (1981) and ' A textbook of translation'(1988) are very useful books for translators and they are full of practical illustrations. Newmark doesn't agree with Nida as far as, ' equivalent effect' is concerned. Newmark feels that success of equivalent effect is illusory and that conflict of loyalties, the gap between emphasis on source and target language will always remain as the riding problem in translation theory and practice.' (Newmark 38) Newmark suggest to fill the gap with semantic and communicative translation.

Communicative translation attempts to produce on its readers an effect as close as possible to that obtained on the readers of the original. Semantic translation attempts to render, as closely as the semantic and syntactic structures of the second language allow, the exact contextual meaning of the original." (Newmark 38) For Newmark semantic translation 'respects context', integrates and explains. Literal translation means, word for word, sticks very closely to the lexis and syntax of the source text. Newmark thinks that the literal translation is the best approach for translation if the translator can achieve the equivalent effect.

In Germany, Werner Koller did influential work in the field of translation. He worked on the concept of equivalence. killer's, 'research into science of translation' (1979) examines the concept of equivalence. He also discusses another similar term i.e. correspondence. (Koller) He points out that, ' while knowledge of correspondence is indicative of competence in foreign language, it is knowledge and ability in equivalence that are indicative of competence in translation. However, the question still remains as to what exactly has to be equivalent? (Koller) To clarify this confusion, he presents five types of equivalence relations:1. denotative equivalence 2 . connotative equivalence 3. text normative equivalence.4. pragmatic equivalence.5. formal equivalence. The concept of equivalence was centre point during and after 1970. The 1970s and 1980s saw a shift in translation theories. It witnessed flourishing of functionalist and communicative approach to translation. 
The functionalist and communicative translation theories progressed in Germany during 1970s-80s. Scholars started looking at the translation from different perspective. It became a kind of intellectual communication. Reiss worked on language function, text type, genre and translation strategy. Another important name in this field is Vermeer. His highly influential work is skopos theory.

Katharina Reiss presents that successful communication depends on the text rather than on word or sentence. functional approach tries to systematize the assessment of translations. she has given three text types and they are summarized by her as: (k. Reiss) 1. Informative text type. 2. Expressive text type. 3. Operative text type. The text types are categorized as per their functions. Katharina Reiss states that, 'the transmission of the predominant functions of the ST is the determining factor by which TT is judged. She also suggests specific translation methods according to text type. She also lists a series of interlinguistic and extralinguistic instruction criteria to measure the adequacy of it.' (K. Reiss) they are linguistic components and Nonlinguistic determinants. These criteria work when TT and ST have same functions. Mary Snell-Hornby has used this as background and researched further. In her book Translation Studies: An integrated approach' (1988, revised 1995) Mary Snell-Hornby reviews different linguistic and literary concepts. She has given the integrated approach to translation. She has borrowed the concept of prototypes from her German theoretical background. She adds cultural history, literary studies, sociocultural and area studies according to the text type by using these prototypes categories of text types. She uses the study of the relevant specialized subject for legal, economic, medical and scientific translations. Reiss approach was later coupled with Veemeer's skopos theory, where translation strategy is decided by the purpose of the translation and the function of the TT in target culture.

The word, 'skopos' was introduced in translation theory in 1970 by Hans j. Vermeer (1930- 2010). It is a Greek word which means. ' aim or purpose'. Vermeer used it is a technical term for the purpose of a translation and of the action of translating. The book, 'Groundwork for General Theory of Translation' by Reiss and Vermeer is a very significant work of skopos theory. skopos theory deals with, "a translatorial action based on a ST- the action has to be negotiated and performed and has a purpose and a result" (Vermeer) Skopos rule shows that, ' the end justifies the means'. (H . Vermeer) Each text is produced for a given purpose and should serve this purpose. 
The skopos rule thus reads as follows: translate/interpret/speak/write in a way that enables your text/translation to function in the situation it is used and with the people who want to use it and precisely in the way they want it to function. There are more than one skopoi and it is the task of translators to justify their choice of a particular skopos. these chosen skopo may need free or faithful translation. It may depend on the purpose of the translation Vermeer also discusses two terms, 'intertextuality' and 'intratextuality' in terms of translation and skopos theory. In this theory workability of translator depends on the target culture. The source text is the part of the belief that receiver helps in making text meaningful. Here different receiver may find different meanings which are offered by the text. The text becomes, ' an offer of information, which is transferred to its receiver.' There is a relationship between ST and TT,' since it is an offer of information about a proceeding offer of information" vermeer call this relationship ' Intertextual coherence' or ' Fieldility'. (Nord) It seems that the main idea of skopos theory is that translation purpose justifies translation procedures.

Thus, functional and communicative theories which advanced in Germany during 1960s- 70sz give translation a different kind of status. Scholars started looking at it as an act of intercultural communication. In Jeremy's words, 'translation is viewed as a communicative transaction involving initiator, commissioner, procedures, users and receivers of the ST and TT'. (Jeremy) Nord's model designed for training translators, retains the functional context but includes a more detailed text-analysis model discussed in discourse and register analysis approaches.

During 1990s discourse analysis became centre point of discussion in translation studies. This approach deals with the ways with which language communicates meaning, social and power relations. this approach is based on the model of Hallidayan systematic functional linguistic. According to Jeremy, "It links micro level linguistic choices to the communicative functions of a text and meaning behind it." (Jeremy) House's $(1977,1997)$ model of register analysis compares a ST- TT pair for situation variables, genre, function and language. Here methods like, ' convert and overt' translation 'errors' are used to identify it. Baker, Hatim and Mason's work brought the pragmatic socio linguistic ideas which can be useful in translation study. Baker's approach helps in focusing on the thematic and cohesive structures of a text. 
Hatim and mason also discussed how social and power relations are translated. This ideological level was further developed in culturally oriented theories.

In 1970 came the reaction to the prescriptive models in the form of Polysystem theory. In the words of Jeremy, " system theory was a reaction to the prescriptive model which saw translated literature as a system operating in the larger social, literary, and historical system of the target culture." (Jeremy) Itamar Even-Zohar, has developed this theory in 1970s. He has taken ideas for this theory from Russian formalists and Czech structuralist. For formalists, literature is the part of the social, cultural, literary and historical framework. For them centre point is the system. EvenZohar thought that translated literature operates as a system in itself:

1. In the way the target language culture selects work for translation.

2. In the way translation norms, behaviours and policies are influenced by other co- systems.

Even-Zohar focuses on the relation between all these systems. He defines the term polysystem as, " multiple system, a system of various systems which intersect with each other and partly overlap, using concurrently different options, yet functioning as one structured whole, whose members are interdependent" (Evan-Zohar). He also talks about the position of translated literature. It is not fixed. It may take a primary or secondary position in the polysystem. He says, " if it is primary, it participates actively in shaping the centre of the polysystems" (Even-Zohar). According to him translated literature takes primary position in following three situations (Even-Zohar). (1). when a young literature is being established. (2) when literature is peripheral or weak. (3) when there is critical turning point in history or there is a vacuum in the literature of the country. If translated literature take secondary position, then it presents a peripheral system within the polysystem. It imparts no influence on the central system. EvenZohar states that, " position occupied by the translated literature in polysystem conditions the translation strategy."(Even-Zohar)

Evan-Zohar's Polysystem theory takes study of translations in the historical and literary system of the target culture. Toury concentrates on descriptive translation study. He wished to find out patterns of behaviour in the translation and to develop the norms of translation process. Translation as rewriting developed from system 
theories. It was Andrew Lefevere who studied power relations and ideologies present in cultural systems that interface with literary translation.

Susan Bassnett and Andre Lefevere in their collection of essays, 'translation, history and culture' advocate interaction between translation and culture. They ask to look at ways in which culture impacts and limits translation. The move from translation as a text to translation as a culture and politics, is what Mary snell-Hornby (1990) in her paper in the same collection, terms, ' cultural turn'. Susan Bessnnett and Andre Lefevere, while focusing on the term, tried to assemble different scholars studying this cultural turn in translation studies. This cultural turn influenced translation study in three areas: translation as Rewriting, translation as Gender and translation and postcolonialism.

Andrew Lefevere's work on translation and culture represents in many ways to cultural turn. His ideas about cultural transfer in translation are present in his book, Translation, Rewriting and the Manipulation of literary Fame (1992). He discusses about the concrete factors which govern the reception, acceptance or rejection of literary texts. He has given the idea of translation as Rewriting which means, any text produced on the basis of another has the intention of adapting that text to a certain ideology or to a certain poetics or to both. He has written in his book, History Translation and Culture with Susan Bassnett (1990):

"Neither the word nor the text, but the culture becomes the operational unit of translation". Another theorist of this theory in translation study is Sherry Simon who in her book Gender in Translation: Cultural Identity and the Politics of Transmission (1996), criticizes translation study for often using the term culture as if it referred to an obvious and unproblematic reality. Simon Sherry looks at translation from a gender study angle in her work, ' Gender in translation: cultural identity and politics of transmission'. (1996) She sees a language of sexism in translation studies. Feminist theorists also see similarity between translated texts and women. This is one of the points of discussion of feminist translation theory. Simon states," for feminist translation, fidelity is to be directed towards neither the author nor the reader, but towards writing project - a project in which both writer and translator participate" (Simon). She has also discussed strategy called, ' treatment of linguistic markers of 
gender'. She concentrates on, ' cultural turn' and its importance in translation studies. She sees the role of cultural studies in the development of translation study as, "Cultural studies brings to translation an understanding of the complexities of gender and culture. It allows us to situate linguistic transfer within the multiple 'post' realities of today: poststructuralism, postcolonialism and postmodernism" (Simon). In the subsequent years it was postcolonialism attracted attention of many translation studies researchers.

Post colonialism was at the centre of discussion in the recent years in translation studies. It generally looks at power relations between colonized and colonizer. Gayatri Spivak discussed about feminist post-colonial and post structuralist approaches in translation in her essay, ' The Politics of Translation' (1993/ 2004). In this essay, she looks at western feminist cultural and ideological turns from different perspective. She thinks that they want feminist writing from outside Europe to get translated in English language which according to her is the language of power. She States, such translation is often expressed in 'translatese' (Spivak) which eliminates the identity of individual and cultures that are politically less powerful and leads to a standardization of very different voices:

"In the act of wholesale translation into English there can be a betrayal of the democratic ideal into the law of the strongest. This happens when all the literature of the third world gets translated into a sort of with- it translates, so that the literature by a woman in Palestine begins to resemble, in the feel of its prose, something by a man in Taiwan." (Spivak)

According to Spivak ' The Politics of Translation' gives importance to English and other languages of ex-colonizers. Translation into this language from non-European countries fails to translate SL view point because translation over assimilates to make it available and comprehensible to western readers. She insists on deep understanding of language and situation of the original. Her theory or approach of translation depends on the post structural rhetoric and she focuses on how cultural studies in post colonialism deals with the translation problems. Spivak thinks that the translation has played an important role in colonization process and in disseminating an ideologically motivated image of colonized people. The word colony refers to an 
inferior translational copy whose suppressed identity has been overwritten by colonizer. Susan Basnett and Harish Trivedi (1999) used the phrase,' shameful history of translation'. These writers discuss issues of post colonialism and translation in their collected essays, post-colonial translation: theory and practice, edited by Susan Bassnett and Harish Trivedi (1999). Translation is seen as battleground and exemplification of the post-colonial context. The terms like 'translational' and 'transnational' also discussed. 'Transnational' refers to those post colonials living between nations as emigrants and also to the 'locational disrupture' that describes the situation of those who remain in the melting pot of their native site. Another important critic this theory is Homi Bhabha. He has discussed the terms like: in-betweenness, the third space, hybridity and cultural difference. Another postcolonial theorist Michael Wolf states, " the translator is no longer a mediator between two different poles, but her/ his activities are inscribed in culture overlapping which imply difference.' (Wolf) Another post-colonial theorist Sathya Rao (2006) is of different opinion than Homi Bhabha. Sathya Rao believes that postcolonial translation is not subversive. Rao has used the term, ' non colonial translation theory'. This theory considers the original as a radical immanence indifferent to the colonial world and therefore untranslatable in to it. (Rao)

Postcolonial writers have their own purposes. Cronin aims, ' to make a distinctive contribution to world culture as a non-imperial English-speaking bridge for the European audio-visual industry' (Cronin). You also have to use appropriate translation strategies to get desired result. He presents the need to protect diversity and ' heterogeneity'. This chapter has discussed literary, linguistic and cultural theories of translation. It moves on to discuss modern philosophical approaches to translation. These approaches have influenced translation studies during second half of twentieth century.

This paper has discussed the literary and linguistic and theories of translation. The current modern features of various approaches still remain to be discussed. There was a kind of interrelation between translation and philosophy during 20th century. Many Eminent Scholars during this era are: George Steiner, Ezra Pound, Walter Benjamin And Derrida. Stainer is known for his Hermeneutic movement. His, ' After Bable' was very influential and very important work of reference for the hermeneutics 
of translation. Steiner defines the hermeneutic approach as, ' the investigation of what it means to understand use of oral or written speech, and the attempt to diagnose this process in terms of a general model of meaning'. (George Steiner) Jeremy in Introducing Translation Studies states, 'After Bable' claims to be the first systematic investigation of theory and processes of translation since the 18th century' (Jeremy). In the beginning he focused on the psychological and intellectual functioning of the mind of the translator then he discussed the process of meaning and translation process. After that he discusses hermeneutically oriented theory and terms it, ' totalizing' model. For him theory of translation means,

" Theory of semantic transfer, must mean one of the two things. It is either an intentionally sharpened, hermeneutically oriented way of designing a working mode of all meaningful exchanges, of the totality of semantic communication.... or it is a sub section of such a model with specific references to interlingual exchanges, to the emission and reception of significant messages between different languages... the 'totalizing' designation is more instructive because it argues the fact that all the procedures of expressive articulation and interpretive reception are translational, weather intra- or interlingually" (Steiner) Steiner sees translation as 'an exact art ' hermeneutic motion consists of four moves:

1. Initiative trust: It presents the idea that translator's first move is ' an investment of belief' believe and trust. there is something in the st that can be understood. Steiner sees this as a concentration of the human way of viewing world symbolically.

2. Aggression: this is an 'incursive' ... 'extractive'... 'invasive' move. For him the translator invades, extracts and brings home. Sometimes Steiner describe the operation involved as 'penetration'(ibid: 314, 319)

3. Incorporation: this refers to how st meaning extracted by the translator in the second movement, is brought in the $t$. He discusses two outcomes here, 1. 'complete domestication'. 2. ' permanent strangeness' and 'marginality'.

4. Compensation: this is also called 'enactment of reciprocity'. This is the crux of metier and morals of the translation.

There has been criticism of Steiner's theory but still his book remains an important contribution to hermeneutic theory of language of translation. Steiner major influence during 20th century was Ezra pound. Steiner refers to both pound and Benjamin as 
'belonging to the age of philosophic- poetic theory and 'definition' (George Steiner) Pound has done this through practice and criticism of translation. Walter Benjamin's essay, The Task of Translation (1969/2004) is originally an introduction to Benjamin's German translation of Baudelaire's, 'Tableaux Parisiens'. It Became very significant book in the field of literary translation. Benjamin criticized modern rationalist and instrumentalist view of language. He saw language as ' magical' and its mission was to reveal spiritual content. Another important work in the field of translation is his essay,' task of the translator'. There he states, "translated texts does not exist to give readers an understanding of the meaning or information content of the original. Instead, it exists separately but in conjunction with the original, coming after it, emerging from its 'afterlife' but also giving the original 'continued life'. This recreation assures survival of original work once it is already out in the world, in ' the age of its fame' (Benjamin). For Benjamin translation expresses the central reciprocal relationship between languages. He states, " A real translation is transparent; does not cover the original, does not block it's light, but allows the pure language, as though reinforced by its own medium, to shine upon the original all the more fully. This may be achieved above all, by a literal rendering of the syntax which proves words rather than sentences to be the primary element of the translator". (Benjamin) He also talks about translator's task to release 'pure language'. He states, "it is the task of the translator release in his own language that pure language which is under the spell of another, to liberate the language imprisoned in a works in his recreation of that work" (Benjamin)

If we talk about the recent activities in translation studies then we must talk about few new technologies: audio visual translation, localization and globalization and corpusbased approach. Corpus based approach is still undervalued. It is important approach for the development of automatic machine translation of various types. localization and globalization are major challenge for translators. One thing is clear from above discussion that one unified theory or approach to translation where all can agree, seems impossible. 


\section{Works Cited}

Benjamin, Walter. "'The task of the translator." The Translation studies Reader (1969/2004): 77, 81,88.

Cronin, M. Translating Ireland:Translation, Languages, Cultures. cork: Cork University Press, 1996.

Evan-Zohar, Itamar. "The positipolysystemon of translated literature within the literary." The Translation Studies Reader (1978/ 2004): 199-204 , 200 , 203.

George Steiner. After Babel: Aspects of Language and Translation. second.

Oxford: Oxford University Press, 1975, 1992, 1998.

H . Vermeer, Katharina Reiss. 'Groundwork for General Theory of Translation'.

Trans. Christiane Nord. Manchester: St. Jerome Publishing, 1984/1997.

Jeremy, Munday. Introducing Translation Studies: Theories and applications.

third. London Newyork: Routledge Taylor and Francis Group, 2012.

Lal, P. "Preface: Shahuntala." Great Sanskrit Plays, in Modern Translation. New York:: New Directions, 1964.

Mukherji, Sujit. "'Personal Commitment: The Craft Not Sullen Art of Translation."." Translation, Text and Theory: the Paradigm of India ( 2002): 25-34.

Newmark, Peter. Approaches to Translation. oxford, Newyork: Pergamon, 1981.

Nord, Christiane. Translating as a purposeful Activity:Functionalist approaches Explained. Manchester: st.Jerome, 1997.

Panikar, K. Ayappa. "'The Anxiety of Authenticity: Reflections on Literary Translation." ." Studies in Translation. (2008.): 66-76.

Rao, Sathya. "From a post colonial to a non colonial theory of translation." (2006): 7394. 
Reiss, katharina. 'Text types, translation types and Translation assessment', ' Reading in translation theory'. Ed. Andrew Chesterman. Trans. Andrew Chesterman. Helsinki: Finn Lectura, n.d.

Reiss, Katharina. Translation criticism: Potential and Limitations. Trans. Errol

F. Rhodes. Manchester: St.Jerome and American Bible Society, $1971 / 2000$.

Simon, Sherry. Gender in Translation: Cultural Identity and the Politics of Transmission. London Newyork: Routledge, 1996.

Sinha, Raman Prasad. " "Theory East and West: Translation in its Different Contexts." Translation, Text and Theory: the Paradigm of India. (2002): 251-66.

Spivak, Gayatri. "The Politics of translation." The translation Readers journal (1993 / 2004): 369-88, 371-2.

Steiner, George. n.d.

Vermeer, H . "'Skopos and commission in translational action'." The Translation Studies Reader (1989/2004): 227-38.

Wolf, Michael. "'The third space in postcolonial representation'." Changing the terms:translating in post colonial era. Ed. simon paul st-Pierre.

University of Ottawa press, 2000. 127-45.

\section{Ms. Urvashi Dave Research Scholar Department of English Veer Narmad South Gujarat University, Surat E-mail: urvashidave24@gmail.com}

